\title{
Subsidies to target specialist outreach services into more remote locations: a national cross-sectional study
}

\author{
Belinda G. O’ Sullivan ${ }^{1,2,3,5}$ BPhysio(Hons), MPH(Hons), GradDipAppEpi, PhD, Research Fellow \\ Matthew R. McGrail ${ }^{2,3}$ BSc(Hons), GradDiplT, PhD, Senior Research Fellow \\ Johannes U. Stoelwinder ${ }^{4}$ MBBS, MD, FRACP, FRACMA, FACHSE, FAFPHM, Chair of Health \\ Services Management and Head, Division of Health Services and Global Health Research \\ ${ }^{1}$ Monash Rural Health, Monash University, Level 3, 26 Mercy Street, PO Box 666, Bendigo, Vic. 3550, Australia. \\ ${ }^{2}$ MABEL Survey: Medicine in Australia: Balancing Employment and Life, Centre for Research Excellence \\ in Medical Workforce Dynamics, Melbourne Institute of Applied Economic and Social Research, \\ Barry Street, Melbourne, Vic. 3010, Australia. \\ ${ }^{3}$ Monash Rural Health, Monash University, Northways Road, Churchill, Vic. 3842, Australia. \\ Email: Matthew.mcgrail@monash.edu \\ ${ }^{4}$ Department of Epidemiology and Preventive Medicine, Monash University, The Alfred, 6th Floor, \\ 99 Commercial Road, Melbourne, Vic. 3004, Australia. Email: just.stoelwinder@monash.edu \\ ${ }^{5}$ Corresponding author. Email: belinda.osullivan@monash.edu
}

\begin{abstract}
Objective. Targeting rural outreach services to areas of highest relative need is challenging because of the higher costs it imposes on health workers to travel longer distances. This paper studied whether subsidies have the potential to support the provision of specialist outreach services into more remote locations.

Methods. National data about subsidies for medical specialist outreach providers as part of the Wave 7 Medicine in Australia: Balancing Employment and Life (MABEL) Survey in 2014.

Results. Nearly half received subsidies: 19\% $(n=110)$ from a formal policy, namely the Australian Government Rural Health Outreach Fund (RHOF), and 27\% $(n=154)$ from other sources. Subsidised specialists travelled for longer and visited more remote locations relative to the non-subsidised group. In addition, compared with non-subsidised specialists, RHOF-subsidised specialists worked in priority areas and provided equally regular services they intended to continue, despite visiting more remote locations.

Conclusion. This suggests the RHOF, although limited to one in five specialist outreach providers, is important to increase targeted and stable outreach services in areas of highest relative need. Other subsidies also play a role in facilitating remote service distribution, but may need to be more structured to promote regular, sustained outreach practice.
\end{abstract}

What is known about this topic? There are no studies describing subsidies for specialist doctors to undertake rural outreach work and whether subsidies, including formal and structured subsidies via the Australian Government RHOF, support targeted outreach services compared with no financial support.

What does this paper add? Using national data from Australia, we describe subsidisation among specialist outreach providers and show that specialists subsidised via the RHOF or another source are more likely to provide remote outreach services.

What are the implications for practitioners? Subsidised specialist outreach providers are more likely to provide remote outreach services. The RHOF, as a formally structured comprehensive subsidy, further targets the provision of priority services into such locations on a regular, ongoing basis.

Additional keywords: policy, remote services, outreach.

Received 4 February 2016, accepted 23 May 2016, published online 4 July 2016

\section{Introduction}

Outreach health services, involving health workers travelling away from their normal practice location to provide services in underserved areas, are widely endorsed to distribute health care to where it is needed. ${ }^{1}$ In Australia, outreach is a key strategy to improve access to medical specialist services in rural areas. ${ }^{2}$ However, ensuring the right mix of services where they are most needed is a significant challenge. Australia is a vast country, with 
many small and isolated towns lacking local services despite higher disease burden. Most Australian specialists base their main practice in metropolitan cities $(85 \%)$ or inner regional towns $(11 \%)$, with generally larger populations $(>50000)$ and within $2 \mathrm{~h}$ travel of the city. ${ }^{3}$ Rural outreach work is undertaken by approximately one in five specialists in Australia, but only $16 \%$ of those specialists participating provide services to remote locations. ${ }^{4}$

The provision of ongoing, regular outreach services into more remote areas typically involves more direct costs to specialist doctors for longer travel and time away from their normal practice. In Australia, specialists have the potential to receive subsidies for these costs: either comprehensive subsidies from a structured national rural outreach policy called the Australian Government Rural Health Outreach Fund (RHOF), directed at priority areas of care, or subsidies from other sources. However, the proportion of specialists working with these subsidies and the effects of these subsidies are unknown. The aim of the present study was to describe the proportion of specialist outreach providers subsidised by the RHOF or other subsidies, and whether subsidies, and specifically RHOF subsidies, target specialist outreach services into more remote locations.

The Australian Government established a structured national outreach policy in 2000 to promote rural outreach work by medical specialists. The policy, called the RHOF since 2012, has been sustained and developed over time. ${ }^{2}$ It currently allocates A \$124.1 million over 4 years (apportioned to multidisciplinary teams), providing capped funding to state and territory fund holders to directly contract specialist doctors who selfnominate to participate. ${ }^{5}$ It is administered on a state and territory basis via a competitive tender process overseen by state- and territory-based independent advisory groups, who prioritise services in outer regional and remote locations that address specific national priority areas, namely chronic diseases, maternal and child health, mental health and eye health. Fees for clinical services are not reimbursed as part of the RHOF, but via Medicare, the Australian Government's health financing scheme, which guarantees a minimum fee-for-service payment to the specialist, regardless of the patient's capacity to pay.

Specialists successfully tendered by the RHOF are able to gain reimbursement for the cost of outreach work for 3 years (reviewed annually), covering the cost of travel and accommodation, loss of income for being absent from the normal practice (non-salaried) or funding to back-fill (salaried). By subsidising these costs via a tender process centred on specific health service priorities, the government intends to increase the regular, ongoing provision of targeted outreach services to smaller, outer regional and remote towns that can demand up to a whole day of travel. ${ }^{6}$

The characteristics of services provided by RHOFsubsidised specialists have not been explored using comparison groups. One part of an evaluation of an earlier version of the policy used modelling and found that policy-subsidised services accounted for a higher proportion of total (including in situ) specialist services in remote $(4.2 \%)$ and very remote areas $(28.7 \%)$ compared with regional areas $(0.7-3.0 \%)$, but parameters in the model were subjective, based on stakeholder consultation about the types of billing practices in specific towns. 7
The range and quality of subsidies from other sources is poorly documented. Examples include subsidisation from oneoff grants from different national government sources, state or territory government or public hospital funds or private industry. ${ }^{8-10}$ These subsidies are likely to support public sector specialists employed on a salary who incur fewer out-of-pocket costs for travel. Subsidies from other sources are less likely to be comprehensive, and more likely to be short term and to target more diverse priorities driven by local, regional or organisational objectives.

Specialists receiving no subsidies for the costs of rural outreach work self-fund their services for diverse reasons. Examples include to improve access and referral to their services and increase patient convenience. ${ }^{6,11}$ However, without financial support, these specialists are likely to minimise travel costs.

\section{Methods}

This study uses data from a large national longitudinal panel survey of Australian doctors, the Medicine in Australia: Balancing Employment and Life (MABEL) study. The primary aim of the MABEL study is to investigate labour supply decisions and their determinants among Australian doctors. The study protocol has been reported elsewhere, ${ }^{12}$ but briefly, in 2008, between June and November, all Australian doctors $(n=54750)$ working clinically were invited to participate (Wave 1). Each subsequent year, all respondents to the previous waves are resurveyed along with new doctors, either those returning to active clinical practice or new graduates.

Herein we report results for specialist doctors surveyed as part of Wave 7 of the MABEL survey, conducted between May and November $2014(n=3505)$. Wave 7 questionnaires included questions about subsidies for outreach work and can be accessed from the study's website (https://mabel.org.au/, accessed 31 May 2016). Analysis of non-response bias specific to the first two waves of the survey has been reported elsewhere, showing the survey respondents were broadly representative. ${ }^{12,13}$ Further, Table 1 describes the characteristics of Wave 7 respondents compared with all Australian specialists.

The MABEL study has ethics approval from The University of Melbourne (Ref. 0709559) and Monash University (Ref. CF07/1102-2007000291).

\section{Cohort}

The present study included specialist doctors who had completed advanced training to gain accreditation with a specialist medical college, working clinically and who travelled to provide outreach services in at least one rural location (between one and three locations could be listed). All locations were geocoded using the Australian Statistical Geography Standard Remoteness Area (ASGS-RA) categories ${ }^{14}$ based on road distance to nearby larger service centres. Rural locations included all categories other than 'Major Cities'. The specialist indicated the location of their main outreach service where they spent the most time in the previous year and was asked additional questions about subsidies, the rate of visiting, travel time, the year the service commenced and intention to continue the service. 
Table 1. Characteristics of medical specialists who responded to the Wave 7 Medicine in Australia Balancing Employment and Life (MABEL) survey, 2014, compared with the Australian specialist workforce

Unless indicated otherwise, data are given as $n(\%)$

\begin{tabular}{lcc}
\hline & $\begin{array}{c}\text { Specialist } \\
\text { respondents } \\
(n=3505)\end{array}$ & $\begin{array}{c}\text { Australian specialist } \\
\text { workforce } \\
(n=27279)^{\mathrm{C}}\end{array}$ \\
\hline Gender & $2260(65)$ & $19681(72)$ \\
$\quad$ Male & $1243(36)$ & $7598(28)$ \\
$\quad$ Female & 51 & 50 \\
Mean age (years) & & \\
Location of main place of work & $2899(83)$ & $21808(86)$ \\
$\quad$ Metropolitan & $606(17)$ & $3601(14)$ \\
$\quad$ Rural & & $5706(21)$ \\
Specialist group & & $1119(4)$ \\
Internal medicine & $762(22)$ & $4250(16)$ \\
$\quad$ Pathology & $127(4)$ & $15306(56)$ \\
$\quad$ Surgery & $380(11)$ & $898(3)$ \\
$\quad$ Other specialists & $1986(57)$ & 44 \\
$\quad$ Missing & $250(7)$ & \\
Mean hours worked per week & 42 & \\
\hline
\end{tabular}

${ }^{\mathrm{A}}$ The number of respondents to age was reduced to 3441 because of 64 missing values. Gender was reduced to 3503 because of two missing values, Mean hours worked was reduced to 3239 because of 266 missing values and Specialist group was reduced to 3255 because of 250 missing values.

B، Internal medicine' included cardiology, endocrinology, gastroenterology and hepatology, general medicine, geriatric medicine, haematology, medical oncology, nephrology, respiratory and sleep medicine, rheumatology, other physician. 'Pathology' included anatomical and general pathology. 'Surgery' included general surgery, otolaryngology, plastic, urology and other surgery. 'Other specialists' included diagnostic radiology, other radiology, obstetrics and gynaecology, paediatrics, anaesthesia, psychiatry, emergency medicine, ophthalmology, dermatology, intensive care unit medicine, rehabilitation medicine, radiation oncology and other specialists not grouped.

${ }^{\mathrm{C}}$ Data on the Australian specialist workforce were obtained from the National Health Workforce Dataset (NHWDS) $2014,{ }^{3}$ except data on 'Location of main place of work', which were obtained from the 2014 Australian Medical Directory dataset $(n=25409) .{ }^{17}$ The NHWDS included 166 specialists whose speciality was general practice under 'other specialists', which is not included as a speciality in the MABEL survey.

During data cleaning, the main outreach service was imputed for a small number of records missing this information based on travel time to the outreach location or as the first rural location visited where travel time was missing.

Specialists who reported the service was Telehealth or retrieval $(n=3)$, visited the outreach location zero times in the past year $(n=4)$ or $\geq 40$ times for an outreach location that was the same town as their main place of work $(n=10)$ and whose main outreach service could not be determined $(n=28)$ were excluded.

\section{Outcome}

Specialists were asked 'Do you currently receive any reimbursement or subsidy for your services to this location (e.g. for travel costs)?' Three groups were compared: those who answered 'Yes, from the Commonwealth, e.g. Rural Health Outreach Fund'; those who answered 'Yes, from another source'; and those who answered 'No'.

\section{Variables}

\section{Characteristics of services}

The time spent travelling from the residential to outreach location was reported as $<1,1$ to 3 or $4+h$. The remoteness of the outreach location was categorised into two groups based on the ASGS-RA categories as 'inner regional' or 'outer regional/remote/very remote'. ${ }^{14}$ Service regularity was measured by the number of times the location was visited in the past year and categorised as $<12$ or $12+$ to reflect a minimum monthly or more regular service. Ongoing service was indicated by the specialist's intention to continue providing the outreach service for $<5$ or $5+$ years.

Specialists also reported the year they started providing their main outreach service, which was converted to a continuous measure of years, with 2014 counted as 1 .

\section{Characteristics of specialists}

Age was categorised to reflect career stages of early-to-mid and mid-to-late career as $<45$ and $45+$ years respectively. Residential location was categorised as 'metropolitan' or 'rural' based on the ASGS-RA categories. Main speciality was selfreported from a list of 50 accredited specialties. An indicator group of specialists working in priority areas of care targeted by the RHOF included general (internal) medicine, ophthalmology, psychiatry, obstetrics and gynaecology, paediatrics, renal medicine, endocrinology, cardiology, respiratory medicine and oncology. ${ }^{5}$ All other specialist types were combined as a reference category, except laboratory-based specialties, which were excluded from the analysis of specialist type because they commonly provide centralised services (all pathology specialties and clinical genetics, clinical haematology, clinical immunology, clinical pharmacology).

Practice type was defined based on weekly hours worked in public hospitals, private hospitals, private consulting rooms or 'other' (aged care, education and other). Two categories were applied: 'public-only' (all hours in public hospital); or 'at least some private work' (one or more hours working in private consultation rooms and/or private hospital). Specialists who reported all or most of their work hours in the 'other' setting and less than $10 \mathrm{~h}$ work in public or private settings were excluded.

\section{Statistical analysis}

Univariate multinomial regression models compared the associations between various characteristics and receiving subsidies from the RHOF, another source or none, reporting relative risk (RR) ratios and 95\% confidence intervals (CI). First, service characteristics (time spent travelling, remoteness of the location visited, service regularity and intention to continue providing the outreach service) were explored. Second, specialist characteristics (age, sex, residential location, practice type and specialist type) were tested. Separate multivariate models 
tested associations between service characteristics and subsidies, accounting for practice sector, as a known influence on outreach service distribution. ${ }^{15}$

\section{Results}

Table 1 shows that the 3505 respondents were broadly comparable with the Australian specialist workforce but included $8 \%$ more females and approximately 5\% fewer surgeons. Of 3505 respondents, 645 provided rural outreach services $(18 \%)$. Of these, 45 were excluded, primarily because the main outreach service was indeterminate. A further 25 were missing information about subsidies, leaving 575 specialists in the final analysis. No exclusion bias was detected by age $(P=0.28)$ or sex $(P=0.07)$. Across the study cohort, $73 \%$ were male, mean age was 45 years, $34 \%$ worked in a rural area and worked a mean of $44 \mathrm{~h}$ per week. Nearly half received some subsidies (110 (19\%) from the RHOF and 154 (27\%) from another source), whereas 311 (54\%) received no subsidies.

Table 2 shows that specialists subsidised in any way were nearly twice as likely to travel $\geq 4 \mathrm{~h}$ and up to four times more likely to visit more remote locations relative to those with no subsidies. RHOF subsidies supported specialists from both metropolitan and rural areas, whereas subsidies from another source primarily supported metropolitan-based specialists.

RHOF-subsidised specialists provided outreach services with similar frequency ( $40 \%$ visiting at least monthly) relative to non-subsidised specialists $(47 \%)$ despite providing services into more remote locations and travelling for longer. In contrast, specialists subsidised from another source were significantly less likely to provide at least a monthly service $(27 \%$; RR $0.40,95 \%$ CI $0.26-0.61)$.
Nearly two-thirds (62\%) of RHOF-subsidised specialists intended to continue visiting for $\geq 5$ years, comparable to nonsubsidised specialists (61\%). Comparatively, those subsidised from another source reported less intention to continue the outreach service, which approached significance $(51 \%$; RR $0.67,95 \%$ CI $0.46-1.0)$. The mean length of outreach service provision was highest for RHOF-subsidised specialists at 11 years, compared with 8 years for specialists with other subsidies and 9 years for those with no subsidies.

Table 3 indicates RHOF-supported specialists were significantly more likely to be among targeted specialties (working in priority areas established by the RHOF) relative to non-subsidised specialists (57\% vs 43\%; RR 1.73, 95\% CI 1.11-2.70). They also more commonly undertook at least some private work (74\% vs 59\%; RR 1.77, 95\% CI 1.07-2.93).

Specialists with subsidies from another source more commonly worked in the public sector relative to non-subsidised specialists (44\% vs 33\%). They were also nearly fourfold more likely to receive a salaried or fixed payment for their outreach service relative to those with no subsidies $(72 \%$ vs $43 \%$ ) (RR 3.50, 95\% CI 2.29-5.31), which was primarily related to the higher proportion of public specialists in this group ( $82 \%$ of whom were paid a salaried or fixed payment).

Accounting for potential confounding by practice sector did not change the results.

\section{Discussion}

The present study provides the first national-level description of subsidies for specialists to undertake rural outreach work and how they relate to service characteristics. Nearly half (46\%) the specialists in the present study received subsidies for the costs

Table 2. Univariate associations between subsidies for rural outreach work and service characteristics of specialist doctors using multinomial logistic regression $(n=575)$

RHOF, Rural Health Outreach Fund, RR, relative risk; CI, confidence interval

\begin{tabular}{|c|c|c|c|c|c|c|c|}
\hline & \multirow{2}{*}{$\begin{array}{c}\text { No subsidy }(n=311) \\
n(\%)\end{array}$} & \multicolumn{3}{|c|}{ Subsidy from another source $(n=154)$} & \multicolumn{3}{|c|}{ RHOF subsidy $(n=110)$} \\
\hline & & $n(\%)$ & $\mathrm{RR}(95 \% \mathrm{CI})$ & $P$-value & $n(\%)$ & $\mathrm{RR}(95 \% \mathrm{CI})$ & $P$-value \\
\hline \multicolumn{8}{|l|}{ Travel time $^{\mathrm{A}}(\mathrm{h})$} \\
\hline$<1$ & $62(20)$ & $12(8)$ & $0.41(0.21-0.79)$ & 0.008 & $11(10)$ & $0.53(0.26-1.06)$ & 0.07 \\
\hline$\geq 4$ & $56(18)$ & $48(31)$ & $1.80(1.14-2.84)$ & 0.012 & $34(31)$ & $1.80(1.08-3.00)$ & 0.024 \\
\hline \multicolumn{8}{|l|}{ Pattern of travel ${ }^{\mathrm{B}}$} \\
\hline Rural to outer regional/remote & $45(15)$ & $18(12)$ & $1.07(0.59-1.96)$ & 0.82 & $20(18)$ & $2.10(1.13-3.88)$ & 0.018 \\
\hline \multicolumn{8}{|l|}{ Frequency of visiting ${ }^{\mathrm{C}}$} \\
\hline Less than monthly & $152(49)$ & $110(71)$ & 1.0 & & $64(58)$ & 1.0 & \\
\hline Monthly or more & $146(47)$ & $42(27)$ & $0.40(0.26-0.61)$ & $<0.0001$ & $44(40)$ & $0.72(0.46-1.12)$ & 0.14 \\
\hline \multicolumn{8}{|l|}{ Intention to continue $\geq 5$ years ${ }^{\mathrm{D}}$} \\
\hline
\end{tabular}

\footnotetext{
${ }^{\mathrm{A}}$ The number of observations for travel time was reduced to 573 because two values were missing from specialists with a subsidy from another source.

${ }^{\mathrm{B}}$ The number of observations for patterns of travel was reduced to 573 because two values were missing from specialists with no subsidy.

${ }^{\mathrm{C}}$ The number of observations for frequency of visiting was reduced to 558 because 17 values were missing (13 for specialists with no subsidy, two for specialists with another subsidy and two for specialists with an RHOF subsidy).

${ }^{\mathrm{D}}$ The number of observations for intention to continue $\geq 5$ years was reduced to 574 because one value was missing from specialists with no subsidy.
} 
Table 3. Univariate associations between subsidies for rural outreach work and specialist doctors' characteristics using multinomial logistic regression $(n=575)$

RHOF, Rural Health Outreach Fund, RR, relative risk; CI, confidence interval

\begin{tabular}{|c|c|c|c|c|c|c|c|}
\hline & \multirow{2}{*}{$\begin{array}{c}\text { No subsidy }(n=311) \\
n(\%)\end{array}$} & \multicolumn{3}{|c|}{ Subsidy from another source $(n=154)$} & \multicolumn{3}{|c|}{ RHOF subsidy $(n=110)$} \\
\hline & & $n(\%)$ & $\mathrm{RR}(95 \% \mathrm{CI})$ & $P$-value & $n(\%)$ & $\mathrm{RR}(95 \% \mathrm{CI})$ & $P$-value \\
\hline \multicolumn{8}{|l|}{$\operatorname{Age}^{\mathrm{A}}$ (years) } \\
\hline$<44$ & $153(49)$ & $69(45)$ & 1.0 & & $54(49)$ & 1.0 & \\
\hline$\geq 45$ & $153(49)$ & $83(54)$ & $1.20(0.81-1.78)$ & 0.35 & $55(50)$ & $1.02(0.66-1.58)$ & 0.93 \\
\hline \multicolumn{8}{|l|}{ Gender } \\
\hline Female & $77(25)$ & $44(29)$ & 1.0 & & $33(30)$ & 1.0 & \\
\hline Public only & $104(33)$ & $68(44)$ & 1.0 & & $26(24)$ & 1.0 & \\
\hline At least some private work & $183(59)$ & $72(47)$ & $0.60(0.40-0.91)$ & 0.02 & $81(74)$ & $1.77(1.07-2.93)$ & 0.03 \\
\hline \multicolumn{8}{|c|}{ Salaried/fixed payment for outreach services ${ }^{\mathrm{C}}$} \\
\hline No & $177(57)$ & $42(27)$ & 1.0 & & $64(58)$ & 1.0 & \\
\hline Yes & $134(43)$ & $111(72)$ & $3.50(2.29-5.31)$ & $<0.0001$ & $46(42)$ & $0.95(0.61-1.47)$ & 0.82 \\
\hline \multicolumn{8}{|l|}{ Targeted specialist type $\mathrm{e}^{\mathrm{D}}$} \\
\hline
\end{tabular}

${ }^{\mathrm{A}}$ The number of observations included in the analysis of age was reduced to 567 because eight values were missing (five for specialists with no subsidy, two for specialists with a subsidy from another source and one for specialists with an RHOF subsidy).

${ }^{\mathrm{B}}$ The number of observations included in the analysis of practice type was reduced to 534 because 39 specialists working only or mostly in 'other' settings (22 specialists with no subsidy, 14 specialists with a subsidy from another source and three specialists with an RHOF subsidy) and two specialists with no subsidy missing hours worked were excluded.

${ }^{\mathrm{C}}$ The number of observations about salaried/fixed payment for services was reduced to 574 because one value was missing for specialists with a subsidy from another source.

${ }^{\mathrm{D}}$ The number of observations included in the analysis of specialist type was reduced to 553 because 22 laboratory-based specialist types were excluded (11 specialists with no subsidy, eight specialists with a subsidy from another source and three specialists with an RHOF subsidy: working in haematology or immunology) and three were missing specialist type (two specialists with no subsidy and one specialist with a subsidy from another source). Targeted specialist types include general medicine, ophthalmology, psychiatry, obstetrics and gynaecology and paediatrics, cardiology, renal physician, endocrinology, oncology and respiratory physicians.

of outreach service provision, relatively evenly split between subsidies from the Australian Government RHOF and subsidies from another source.

Receiving subsidies of any type was associated with specialist doctors travelling for longer and providing more remote services. In addition, RHOF subsidies were correlated with specialists working in priority areas, who provided equally regular services they intended to continue relative to non-subsidised specialists despite visiting more remote locations. This suggests the competitive tender process centred on national priorities is working well. Further, the signs that outreach services by RHOFsubsidised specialists are likely to be more stable could be related to the comprehensive nature of these subsidies, including provisions for back-filling, team support and re-contracting after 3 years. However, the capacity to influence remote health priorities depends on continued government funding in the same priority areas, as well as consistent service provision to the same population catchments.

The RHOF appears well targeted at private specialists based in both metropolitan and rural areas. Previous research has shown that specialists based in inner regional locations are less likely to provide remote outreach services, ${ }^{4}$ private rural specialists restrict their travel distance likely because of poorer access to expedient transport ${ }^{15}$ and private specialists overall are less likely to sustain rural outreach services. ${ }^{16}$

Specialists with non-RHOF subsidies were likely to be employed in the public sector, incurring fewer out-of-pocket costs for outreach work, regardless of clinical throughput. Although non-RHOF subsidies were related to more remote service provision, the finding of irregular service provision is potentially related to a predetermined service schedule by public hospitals, restricted funding or difficulty back-filling the normal role to cover the hospital workload. Regardless of a lower intention for ongoing practice, the group receiving subsidies from other sources still had a reasonable mean 8 years of providing rural outreach service.

Commonly, specialists providing rural outreach services without any subsidies were reliant on fee-for-service reimbursements (57\%), rather than receiving a salary or fixed payment for services at the outreach location. Perhaps driven by a financial imperative to balance the direct costs of outreach work against the potential revenue available via a fee-for-service payment for clinical services, this group tended to provide outreach service to nearby inner regional locations. The policy benefit is that through necessity, the group with no subsidies is likely to practice outreach in a self-sustaining way, with intent to continue rural 
outreach services similar to the RHOF-subsidised group (61\% vs $62 \%$ ).

The RHOF is a unique policy intervention aiming to mobilise specialists to areas of need. ${ }^{2}$ Compared with financial incentives to promote permanent recruitment and retention in rural and remote areas, the RHOF represents modest expenditure, which is flexible to adjust workforce redistribution according to specific priorities. The findings of the present study are applicable to other developed nations grappling with the mobilisation of a highly centralised and privatised workforce into geographically dispersed rural communities with specific health needs.

We postulate that the capacity for policies subsidising health workers to make a difference to rural and remote health outcomes depends on the level workforce interest, the autonomy of health workers to participate, the amount of funding and proportion of rural outreach services the funding can support. In Australia, where population densities are small and distances can be extreme, travel is expensive and time consuming. Other more densely populated countries may spend less to achieve improved access in under-served areas.

\section{Limitations}

The present study was limited to reporting about subsidies for the main outreach service only, rather than secondary outreach services the specialists may provide. Basing the research on the location where the specialist spent the most time may have biased the study to larger towns, such that an underestimation of remote outreach work is likely. The present study was unable to determine the exact qualities and size of subsidies provided from the RHOF or other sources, because these can be packaged up differently according to individual needs and local-level factors. Although the study was limited to exploring associations rather than causal relationships, it provides the first national-level evidence describing subsidisation for rural outreach.

\section{Conclusion}

Specialists subsidised for rural outreach work were more likely to travel for longer and provide services into more remote locations than non-subsidised specialists. In addition, compared with specialists with no subsidies, RHOF-subsidised specialists worked in priority areas and provided equally regular services they intended to continue, despite visiting more remote locations. This suggests the RHOF subsidies, although limited to one in five specialist outreach providers, is important to increase targeted and stable outreach services in areas of highest relative need. Subsidies from other sources also play a role in facilitating remote service provision, but they may need to be better structured to promote regular and sustained practice.

\section{Competing interests}

None declared.

\section{Acknowledgements}

This publication used data from the MABEL longitudinal survey of doctors conducted by The University of Melbourne and Monash University (the
MABEL research team). Funding for MABEL comes from the National Health and Medical Research Council (Health Services Research Grant: 2008-2011; and Centre for Research Excellence in Medical Workforce Dynamics: 2012-2016) with additional support from the Department of Health (in 2008) and Health Workforce Australia (in 2013). BGO was supported by an Australian Postgraduate Award.

\section{References}

1 de Roodenbeke E, Lucas S, Rouzaut A, Bana F. Outreach services as a strategy to increase access to health workers in remote and rural areas. Technical report no. 2. Geneva: World Health Organization International Hospital Federation; 2011. Available at: http://whqlibdoc.who.int/publications/2011/9789241501514_eng.pdf [verified 31 May 2016].

2 O'Sullivan BG, Joyce CM, McGrail MR. Adoption, implementation and prioritization of specialist outreach policy in Australia: a national perspective. Bull World Health Organ 2014; 92: 512-19. doi:10.2471/BLT. 13.130385

3 Australian Institute of Health and Welfare (AIHW). National health workforce data set. Medical practitioners 2014. Canberra: AIHW; 2015. Available at: http://www.aihw.gov.au/workforce/medical/addi tional/ [verified 31 May 2016].

4 O'Sullivan B, Joyce C, McGrail M. Rural outreach by specialist doctors in Australia: a national cross-sectional study of supply and distribution. Hum Resour Health 2014; 12: 1-10. doi:10.1186/1478-4491-12-50

5 Department of Health and Ageing. Rural Health Outreach Fund service delivery standards: rural and regional health Australia. Canberra: Department of Health and Ageing; 2012. Available at: http://www. ruralhealthaustralia.gov.au/internet/rha/publishing.nsf/Content/RHOFservice-delivery-standards [verified 31 May 2016].

6 Gadiel D, Ridoutt L, Bune A, Cheang C, Cook K, Thiele D. Evaluation of outreach models of medical specialist service delivery. Sydney: Human Capital Alliance International; 2004. Available at: http://www.human capitalalliance.com.au/downloads/DH28\%20Specialist\%20outreach\% 20model\%20evaluation.PDF [verified 31 May 2016].

7 Health Policy Analysis. Evaluation of the Medical Specialist Outreach Assistance Program and the Visiting Optometrists Scheme: final report, volume 1. Canberra: Department of Health and Ageing; 2011. Available at: http://www.ruralhealthaustralia.gov.au/internet/rha/publishing.nsf/ Content/B5834BF6038FA090CA257A4C00255757/\$File/DoHA-Eva luation_of_MSOAP_and_VOS_final_report_Volume $\% 201 . p d f$ [verified 31 May 2016].

8 Broadbent A, McKenzie J. Wagga Wagga specialist outreach palliative medicine service: a report on the first 12 months of service. Aust J Rural Health 2006; 14: 219-24. doi:10.1111/j.1440-1584.2006. 00813.x

9 Gruen RL, Weeramanthri TS, Bailie RS. Outreach and improved access to specialist services for indigenous people in remote Australia: the requirements for sustainability. J Epidemiol Community Health 2002; 56: 517-21. doi:10.1136/jech.56.7.517

10 Goss PW, Paterson MA, Renalson JA. 'Radical' new rural model for pediatric diabetes care. Pediatr Diabetes 2010; 11: 296-304. doi:10.11 11/j.1399-5448.2009.00594.x

11 Chittleborough T, Lourensz K, Elliot M, Thomas P, Franzi S. Outreach surgical consulting services in North East Victoria. Aust J Rural Health 2013; 21: 325-8. doi:10.1111/ajr.12065

12 Joyce C, Scott A, Jeon S-H, Humphreys J, Kalb G, Witt J, Leahy A. The 'Medicine in Australia: Balancing Employment and Life (MABEL)' longitudinal survey: Protocol and baseline data for a prospective cohort study of Australian doctors' workforce participation. BMC Health Serv Res 2010; 10: 50. doi:10.1186/1472-6963-10-50

13 Yan W, Cheng TC, Scott A, Joyce CM, Humphreys J, Kalb G, Leahy A. Medicine in Australia: Balancing Employment and Life (MABEL). Aust Econ Rev 2011; 44: 102-12. doi:10.1111/j.1467-8462.2010. 00627.x 
14 Australian Bureau of Statistics (ABS). The Australian statistical geography standard (ASGS) remoteness structure. Canberra: ABS; 2011. Available at: http://www.abs.gov.au/websitedbs/d3310114.nsf/home/ remoteness+structure\#Anchor1 [verified 31 May 2016].

15 O'Sullivan B, Stoelwinder J, Joyce C, McGrail M. Service distribution and models of rural outreach by specialist doctors in Australia: a national cross-sectional study Aust Health Rev 2016; 40: 330-6. doi:10.1071/ AH15100
16 O'Sullivan B, Stoelwinder J, McGrail M. The stability of rural outreach services: a national longitudinal study of specialist doctors. Med J Aust 2015; 203: 297e1-e6. doi:10.5694/mja15.00369

17 Australasian Medical Publishing Company (AMPCo) Direct. Australian medical directory dataset. Sydney: AMPCo Direct; 2008. 